\title{
Peertechz
}

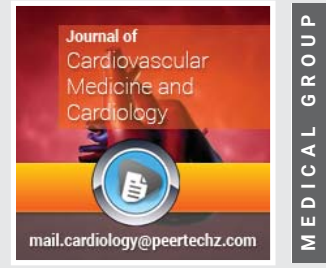

\section{Return to Former Activities of Daily Living for Cardiovascular Patients in COVID-19}

\author{
Muharrem Said Cosgun ${ }^{1}$, Cansu Cosgun ${ }^{2}$ and Husnu \\ Degirmenci ${ }^{1 *}$
}

'Department of Cardiology, Faculty of Medicine, Erzincan Binali Yıldırım University, Turkey

Check for updates

Received: 10 February, 2021

Accepted: 19 February, 2021

Published: 20 February, 2021

*Corresponding author: Husnu Degirmenci, Faculty of Medicine, Department of Cardiology, Erzincan Binali Yildirim University, Erzincan, Turkey,

E-mail: husnudr1982@gmail.com

ORCID: http://orcid.org/0000-0003-0618-7227

Keywords: COVID-19; Activities of daily living; Cardiovascular; Comorbidites

https://www.peertechz.com

${ }^{2}$ Department of Physical Therapy and Rehabilitation, Faculty of Medicine, Erzincan Binali Yıldırım

University, Turkey

\section{Abstract}

Background: Coronavirus disease 2019 (COVID-19) was declared a pandemic by the World Health Organization in March 2020. Despite all the strict precautions, the epidemic probably continues rapidly due to new mutations and negatively affects the whole world. The presence of comorbid diseases has been associated with poor clinical outcomes. We aimed to examine the return of COVID-19 patients with cardiovascular comorbidity to their former Activities of Daily Living (ADL).

Methods: The research population was selected from patients who admitted to the outpatient clinic from November 2020 to January 2021 . 80 consecutive patients with cardiovascular comorbidity were included in the Study Group (SG). The Control Group (CG) included 100 patients of similar age range and gender, without cardiovascular comorbidities. Nottingham Health Profile (NHP) test was performed in both groups to evaluate changes in ADL. Outpatients were visited until return to their former ADL with telecommunications at appropriate intervals.

Results: Symptoms limiting ADL, such as fatigue (weakness), shortness of breath, and myalgia, were significantly higher in SG than CG ( $<$ < 0.05 ). In contrast, anosmia and ageusia were significantly higher in CG than SG ( $<<0.001)$. Pre-COVID-19 NHP scores were similar in both groups. However, at admission, SG's NHP scores were significantly higher than CG's $(p<0.001)$. Related to this, limitations in ADL $(p<0.001)$ and recovery times $(p<0.05)$ were higher in SG than CG.

Conclusion: In this study, we observed that COVID-19 was more symptomatic in those with cardiovascular comorbidities, such as a higher limitation in ADL and a longer recovery time.

\section{Introduction}

The coronavirus disease 2019 (COVID-19), which started to spread from the wet animal market in the state of Wuhan in China at the end of 2019, was declared as a pandemic by the World Health Organization in March 2020 [1]. This is the third outbreak by coronaviruses in the 21st century. Until 20 years ago, coronavirus infections were known to cause mild respiratory illness [2]. However more than 100 million people have already been infected with this virus, and more than 2 million people have died from COVID-19 related causes [3]. Despite vaccination, strict precautions, and the lock-down, the outbreak continues rapidly, likely due to new mutations, and negatively affecting the whole world [4].

While COVID-19 is known to primarily affect the lung system, its impact extends far beyond the respiratory system and affects other organs of the body. Extrapulmonary symptoms of COVID-19 (cardiovascular, renal, hepatic, gastrointestinal, ocular, dermatological, and neurological) are more common than is thought [5]. The clinical course of the disease is usually mild, less frequently severe, and critical $(81 \%, 14 \%$, and $5 \%$, respectively) [6]. Cough and fever (above $37.8^{\circ}$ ) are the most common symptoms at admission and are present at $67.8 \%$ and $43.8 \%$, respectively. In addition, symptoms that limit Activities of Daily Living (ADL) such as fatigue (lassitude), shortness of breath, and myalgia are common $(38.1 \%, 18.7 \%$, and $14.7 \%$, respectively) $[7,8]$. The presence of comorbid diseases has been associated with poor clinical outcomes such as prolonged hospitalization, increased referral for intensive care units, and death [9-13]. Based on this informations, we aimed to examine 
COVID-19 patients with cardiovascular comorbidity the return to their former ADL.

\section{Materials and methods}

\section{Ethics committee approval}

Ethics committee approval was received from the "Clinical Research Ethics Committee of Erzincan Binali Yıldırım University" (Chairperson: Kezban Meltem ÇOLAK, date: 07/07/2020, meeting no: 07 and protocol number: 06) also from the "Republic of Turkey Ministry of Health". Patients have given their informed consent for participation in the research study.

\section{Study design}

The study population was selected from patients who admitted to the outpatient clinic between November 2020 and January 2021. Those with orthopedic and neurological diseases and asymptomatic patients were excluded. 80 consecutive patients with cardiovascular comorbidity were included in the Study Group (SG). The Control Group (CG) included 100 patients of similar age range and gender to avoid selection bias, without cardiovascular comorbidities. Cardiovascular comorbid diseases were accepted as Hypertension (HT), Coronary Artery Disease (CAD), and heart failure (HF). All patients were in the mild disease group according to the definitions in the "COVID-19 (SARS-CoV-2 INFECTION) GUIDE" published by the Republic of Turkey Ministry of Health and hospitalization was not required. Mild illness presents with features such as fever, muscle/joint pain, cough, sore throat, and nasal congestion, with or without mild pneumonia together with a respiratory rate $<30 / \mathrm{min}$ and an 02 saturation above $90 \%$ while breathing room air [14]. The reverse transcriptionpolymerase chain reaction was positive in the nasopharyngeal swab in all patients. Demographic and clinical characteristics of all patients were recorded. Nottingham Health Profile (NHP) test was performed in both groups to evaluate changes in ADL [15]. While performing the NHP test, two different results were obtained considering both the current and previous conditions of the patients. The limitations in ADL were calculated by the difference between the two results. Outpatients were visited until return to their former ADL with telecommunications at appropriate intervals. The data obtained from both groups were compared with each other.

\section{Statistical analysis}

The data obtained were analyzed using an SPSS 20.0 software for Windows (SPSS Inc, Chicago, IL) and checked for suitability for a normal distribution with the Shapiro-Wilk test. All categorical data were studied with the chi-square test. The threshold for significance was defined at $\mathrm{p}<0.05$.

\section{Results}

The age, gender distributions, and body mass index of both groups were similar. Smoking habit in CG and diabetes mellitus in SG was higher significantly $(\mathrm{p}<0.001)$. There was no difference between the two groups in other comorbidities such as pulmonary disease and renal failure (Table 1). The most common cardiovascular comorbidity was HT (85\%), followed by CAD (30\%) and HF (15\%), respectively (Figure 1). The cough and fever were the most common symptoms in both groups, similarly. Symptoms that limit ADL such as fatigue (lassitude), shortness of breath, and myalgia were significantly higher in SG than CG ( $p<0.05)$. In contrast, anosmia and ageusia were significantly higher in CG than SG $(\mathrm{p}<0.001)$ (Figure 2). PreCOVID-19 NHP scores were similar in both groups. However, at admission, SG's NHP scores were significantly higher than CG's $(\mathrm{p}<0.001)$. As a result, limitations in ADL $(\mathrm{p}<0.001)$ and recovery times $(\mathrm{p}<0.05)$ were higher in SG than CG (Table 2, Figure 3).

\begin{tabular}{|c|c|c|c|}
\hline Table 1: Demographic characteristics of the patients. \\
\hline $\begin{array}{c}\text { Demographic } \\
\text { characteris }\end{array}$ & $\begin{array}{c}\text { Study group } \\
(\mathbf{n = 8 0})\end{array}$ & $\begin{array}{c}\text { Control group } \\
(\mathbf{n = 1 0 0 )}\end{array}$ & $\mathbf{p}$ \\
\hline Age (Years \pm SD) & $56 \pm 17$ & $55 \pm 16$ & 0.565 \\
\hline Male gender & $65 \%$ & $63 \%$ & 0.743 \\
\hline Body mass index & 24.6 & 24.2 & 0.196 \\
\hline Smoking habit & $20 \%$ & $32 \%$ & $<0.001$ \\
\hline Diabetes mellitus & $28.75 \%$ & $8 \%$ & $<0.001$ \\
\hline Pulmonary disease & $15 \%$ & $13 \%$ & 0.126 \\
\hline Renal Failure & $2.5 \%$ & $2 \%$ & 0.325 \\
\hline
\end{tabular}

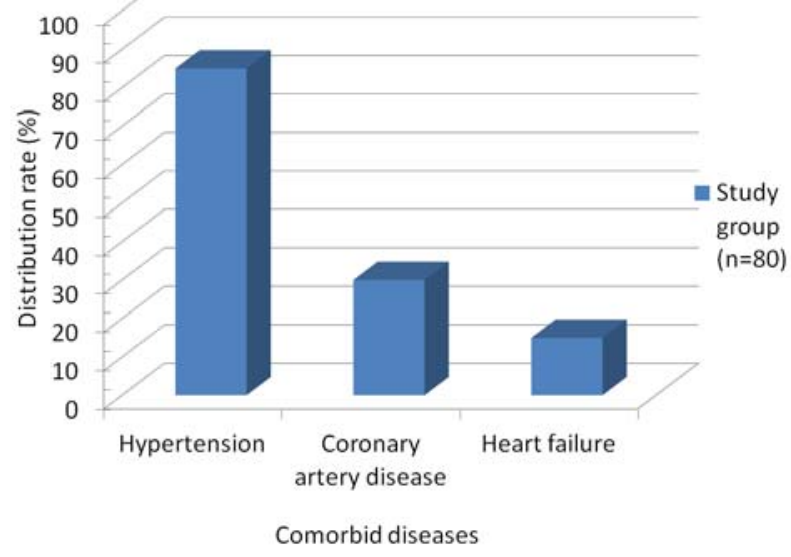

Figure 1: Distribution of cardiovascular comorbidities in the study group.

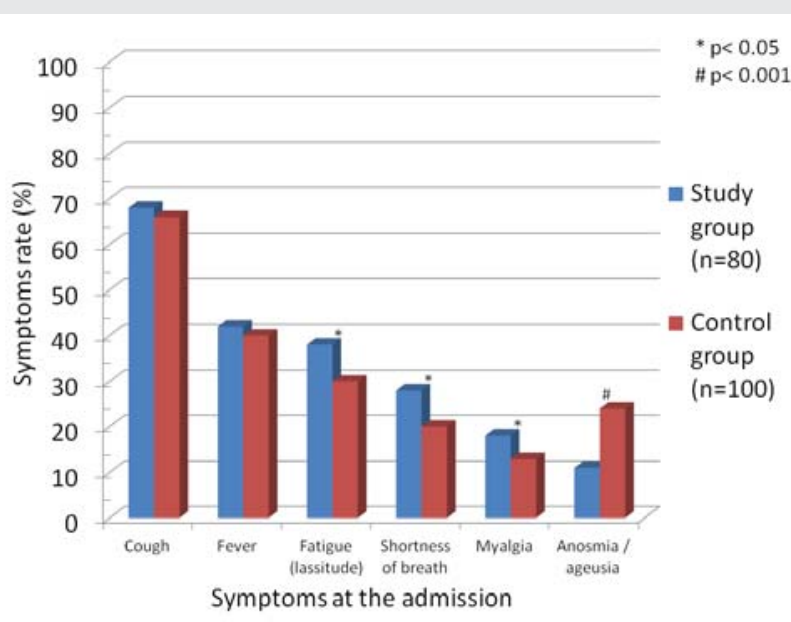

Figure 2: Symptoms of the patients. 
Table 2: Nottingham Health Profile test results of the patients.

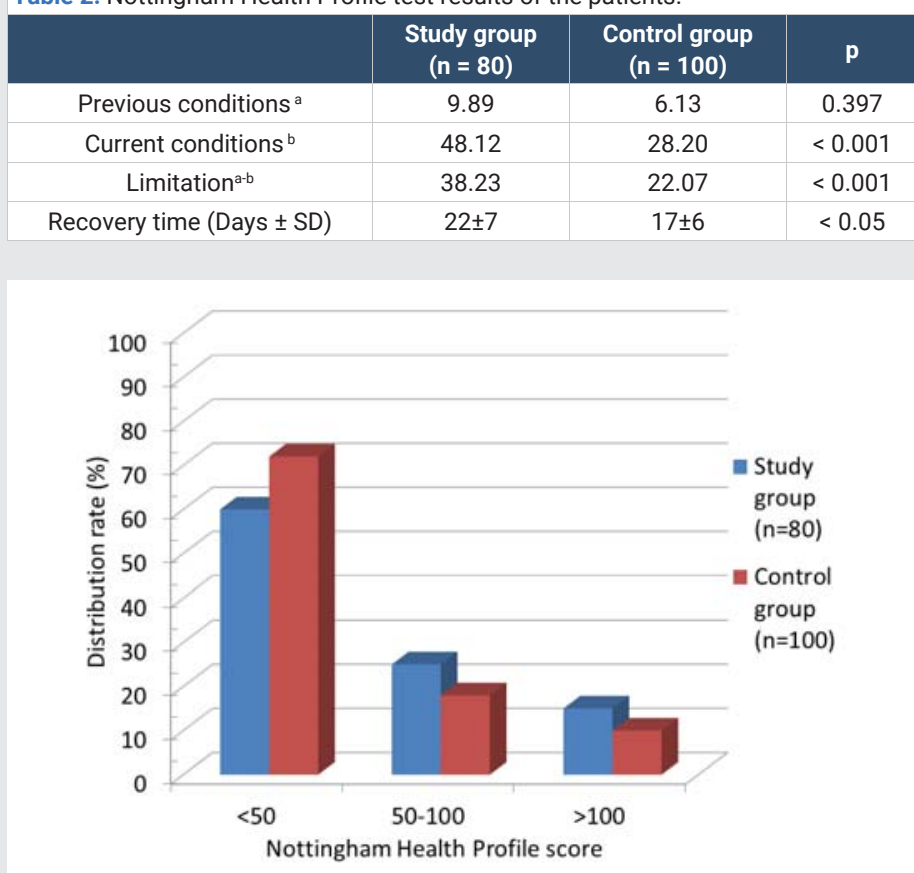

Figure 3: Distribution rate of Nottingham Health Profile test results.

\section{Discussion}

SARS-CoV-2 infection can cause heart damage through a variety of mechanisms, including the expression of the angiotensin-converting enzyme 2 receptors, leading to a cytokine storm, can elicit an exaggerated host immune response [16].

The present study is based on the observation of COVID-19 outpatients. The relationship between the presence of cardiovascular comorbidities and limitations in ADL was studied in patients with mild disease.

There was no difference in demographic characteristics of the patients except for their smoking habits. Likewise, the basic symptoms of the disease were similar. Patients with cardiovascular comorbidity had a higher limitation in ADL and longer recovery time. The excess of these signs indicates that the disease is more symptomatic in this group [17]. In contrast, symptoms such as anosmia and ageusia were more common in those without comorbid diseases. The more frequent upper respiratory tract symptoms indicate that the disease is milder $[18,19]$.

\section{Conclusion}

In this study, we observed that COVID-19 was more symptomatic in those with cardiovascular comorbidities, such as a higher limitation in ADL and a longer recovery time.

limitations of the study: The most important limitations of our study are the low number of patients and conducted single center.

\section{References}

1. WHO. World Health Organization. Link: https://bit.ly/3sdKLFj

2. Mann R, Perisetti A, Gajendran M, Gandhi Z, Umapathy C, et al. (2020) Clinical Characteristics, Diagnosis, and Treatment of Major Coronavirus Outbreaks. Front Med (Lausanne) 7: 581-521. Link: https://bit.ly/3s7R9xF

3. WHO. World Health Organization. Link: https://bit.ly/3k59Ejn

4. Baric RS (2020) Emergence of a Highly Fit SARS-CoV-2 Variant. N Engl J Med 383: 2684-2686. Link: https://bit.ly/3pC5PDD

5. Johnson KD, Harris C, Cain JK, Hummer C, Goyal H, et al. (2020) Pulmonary and Extra-Pulmonary Clinical Manifestations of COVID-19. Frontiers in Medicine 7: 526. Link: https://bit.ly/2NGUMvL

6. Wu Z, McGoogan JM (2020) Characteristics of and important lessons from the coronavirus disease 2019 (COVID-19) outbreak in China: summary of a report of 72314 cases from the Chinese Center for Disease Control and Prevention. JAMA 323: 1239-1242. Link: https://bit.ly/3dp5QbH

7. Guan WJ, Ni ZY, Hu Y, Liang WH, Ou CQ, et al. (2020) Clinical characteristics of coronavirus disease 2019 in China. New England Journal of Medicine 382: 1708-1720. Link: https://bit.ly/3uf0QvZ

8. CfDCaP Centers for Disease Control and Prevention Link: https://bit. $\mathrm{ly} / 3 \mathrm{~s} 63 \mathrm{Wkc}$

9. Chen T, Wu D, Chen H, Yan W, Yang D, et al. (2020) Clinical characteristics of 113 deceased patients with coronavirus disease 2019: retrospective study. BMJ 368. Link: https://bit.ly/3biX1gM

10. Du RH, Liu LM, Yin W, Wang W, Guan LL, et al. (2020) Hospitalization and critical care of 109 decedents with COVID-19 pneumonia in Wuhan, China. Ann Am Thorac Soc 17: 839-846. Link: https://bit.ly/3qCgEqq

11. Richardson S, Hirsch JS, Narasimhan M, Crawford JM, McGinn T, et al. (2020) Presenting characteristics, comorbidities, and outcomes among 5700 patients hospitalized with COVID-19 in the New York City area. JAMA 323: 2052-2059. Link: https://bit.ly/37vYzTz

12. Zhou F, Yu T, Du R, Fan G, Liu Y, et al. (2020) Clinical course and risk factors for mortality of adult inpatients with COVID-19 in Wuhan, China: a retrospective cohort study. Lancet 395: 1054-1062. Link: https://bit.ly/3s94bep

13. Liang WH, Guan WJ, Li CC, Li YM, Liang HR, et al. (2020) Clinical characteristics and outcomes of hospitalised patients with COVID-19 treated in Hubei (epicentre) and outside Hubei (non-epicentre): a nationwide analysis of China. Eur Respir J 55: 2000562. Link: https://bit.ly/3pA6yFh

14. RoTMoH. Republic of Turkey Ministry of Health Link: https://bit.ly/3k5j3rp

15. NHP Nottingham Health Profile. Link: https://bit.ly/3k4PIgK

16. Li N, Zhu L, Sun L, Shao G (2021) The effects of novel coronavirus (SARSCoV-2) infection on cardiovascular diseases and cardiopulmonary injuries. Stem cell Res 51: 102168. Link: https://bit.ly/3dtnZ8k

17. Liu Y, Yan LM, Wan L, Xiang TX, Le A, et al. (2020) Viral dynamics in mild and severe cases of COVID-19. Lancet Infectious Dis 20: 656-657. Link: https:// bit.ly/3k4Qj1Y

18. Mendonça CV, Neto JAM, Suzuki FA, Orth MS, Neto HM, et al. (2021) Olfactory dysfunction in COVID-19: a marker of good prognosis? Braz J Otorhinolaryngol S1808-8694(20)30240-8. Link: https://bit.ly/37tzHfe

19. Sanli DET, Altundag A, Kandemirli SG, Yildirim D, Sanli AN, Saatci O, et al. (2021) Relationship between disease severity and serum IL-6 levels in COVID-19 anosmia. m J Otolaryngol 42: 102796. Link: https://bit.ly/3s9JfE1

Copyright: ๑ 2021 Cosgun MS, et al. This is an open-access article distributed under the terms of the Creative Commons Attribution License, which permits unrestricted use, distribution, and reproduction in any medium, provided the original author and source are credited. 